\title{
The Role of Physical Exercise on Lipid Peroxidation in Diabetic Complications
}

\author{
Yaşar Gül Özkaya
}

Additional information is available at the end of the chapter

http://dx.doi.org/10.5772/46182

\section{Introduction}

Diabetes mellitus is a group of metabolic disorder characterized by hyperglicemia and insufficiency of action or secretion of insulin. More than 346 million people worldwide have diabetes. 80 per cent of diabetes-induced deaths ocur in low- and middle-income countries. Most people with diabetes are above the age of retirement in developed countries, whereas in developing countries those most frequently affected are aged between 35 and 64 [1]. Although the etiology of this disease is not well defined, viral infections, autoimmunity, genetic and environmental factors have been implicated [2-5]. Four major types of diabetes have been defined by the American Diabetes Association (ADA): type 1 diabetes, type 2 diabetes, other spesific types of diabetes and gestational diabetes mellitus (GDM) [6].

Type 1 diabetes (T1D) usually develops in childhood and adolescence and the cause of the disease is an absolute deficiency of insulin secretion. Individuals at increased risk of developing this type of diabetes can often be identified by serological evidence of an autoimmune pathologic process occurring in the pancreatic islets and by genetic markers [6].

Type 2 diabetes (T2D) usually develops in adulthood and is related to obesity, lack of physical activity, and unhealthy diets. This is the more common type of diabetes (representing $90 \%$ of diabetic cases worldwide) and the cause is a combination of resistance to insulin action and an inadequate compensatory insulin secretory response. In Type 2 diabetes, a degree of hyperglycemia sufficient to cause pathologic and functional changes in various target tissues, but without clinical symptoms, may be present for a long period of time before diabetes is detected. During this asymptomatic period, it is possible to demonstrate an abnormality in carbohydrate metabolism by measurement of plasma glucose in the fasting state or after a challenge with an oral glucose load. 
The third category "other spesific types of diabetes" includes diabetes caused by a spesific and identified underlying defect, such as genetic syndromes, acquired processes such as pancreatitis, diseases such as cystic fibrosis, exposure to certain drugs, viruses, and unknown causes. Gestational diabetes is a state of hyperglicemia which develops during pregnancy [6].

Currently, ADA recommends the use of any of the following four criteria for diagnosing diabetes: 1) glycated hemoglobin (A1c) value of $6.5 \%$ or higher, 2 ) fasting plasma glucose $\geq$ $\left.126 \mathrm{mg} . \mathrm{dL}^{-1}\left(7.0 \mathrm{mmol} . \mathrm{L}^{-1}\right), 3\right)$ 2-h plasma glucose $\geq 200 \mathrm{mg} \cdot \mathrm{dL}^{-1}\left(11.1 \mathrm{mmol} . \mathrm{L}^{-1}\right)$ during an oral glucose tolerance test using $75 \mathrm{~g}$ of glucose, and/or 4) classic symptoms of hyperglycemia (e.g., polyuria, polydipsia, and unexplained weight loss) or hyperglycemic crisis with a random plasma glucose of $200 \mathrm{mg} \cdot \mathrm{dL}^{-1}\left(11.1 \mathrm{mmol} . \mathrm{L}^{-1}\right)$ or higher. In the absence of unequivocal hyperglycemia, the first three criteria should be confirmed by repeat testing [6].

Hyperglycaemia and hyperlipidaemia are key promoters of diabetes dysmetabolism, namely, through the formation of reactive oxygen species (ROS) and advanced glycation end products (AGEs), which causes cell damage and insulin resistance [7-9]. Moreover, both of them stimulate proinflammatory cytokines, thus contributing to $\beta$-cell degradation, particularly due to apoptosis pathways [10].

Increased oxidative stress is a widely accepted participant in the development and progression of diabetes and its complications [11-13]. Diabetes is usually accompanied by increased production of free radicals [14,15] or impaired antioxidant defenses [16]. Mechanisms by which increased oxidative stress is involved in the diabetic complications are partly known, including activation of transcription factors, advanced glycated end products (AGEs) [2], and protein kinase C [17].

Modern medical care uses a vast array of lifestyle and pharmaceutical interventions aimed at preventing and controlling hyperglycemia. In addition to ensuring the adequate delivery of glucose to the tissues of the body, treatment of diabetes attempts to decrease the likelihood that the tissues of the body are harmed by hyperglycemia. The importance of protecting the body from hyperglycemia cannot be overstated; the direct and indirect effects on the human vascular tree are the major source of morbidity and mortality in both type 1 and type 2 diabetes. Generally, the injurious effects of hyperglycemia are separated into macrovascular complications (coronary artery disease, peripheral arterial disease, and stroke) and microvascular complications (diabetic nephropathy, neuropathy, and retinopathy) [11].

Physical activity (PA) and diet are cornerstones of diabetes therapy [19]. Physical activity is a multifaceted behavior of which exercise is just one component. PA is defined as "bodily movement produced by the contraction of skeletal muscle that substantially increases energy expenditure" and exercise is defined as "a subset of PA done with the intention of developing physical fitness (i.e., cardiovascular, strength, and flexibility training)." [19]. In this chapter, PA and exercise is used interchangeably. 
In last decades, an impressive body of research has accumulated that demonstrates the varied benefits of regular physical activity for people with type 1 or type 2 diabetes [20]. Notably, exercise has been shown to improve glycemic control, reduce the need for insulin and oral hypoglycemic agents, and improve body weight control. Exercise has been shown to promote beneficial effects on insulin resistance, both in humans and in rodent models of T2DM [21, 22]. Moreover, exercise has myriad benefits for all people beyond those relating to diabetes alone. It can work wonders for the heart, improving the lipid profile, reducing risk for heart disease, restoring function after a heart attack, and moderating blood pressure. It helps in maintaining bone health regardless of age, it can significantly relieve depression and anxiety, and it appears to help maintain cognitive function in old age [23, 24]. A correlation between the effects of acute and chronic aerobic exercise upon oxidative stress and inflammation and the diabetic dysmetabolism has been previously described [25-27].

This chapter focuses on recent clinical and experimental studies of diabetes and exercise interventions done within the context of lipid peroxidation.

\section{Lipid peroxidation and diabetic complications}

\subsection{Overview of lipid peroxidation and diabetic complications}

Excessively high levels of free radicals cause damage to cellular proteins, membrane lipids and nucleic acids, and eventually cell death [2]. Various mechanisms have been suggested to contribute to the formation of these reactive oxygen-free radicals in diabetic state. Glucose oxidation is believed to be the main source of free radicals. In its enediol form, glucose is oxidized in a transition-metal dependent reaction to an enediol radical anion that is converted into reactive ketoaldehydes and to superoxide anion radicals. The superoxide anion radicals undergo dismutation to hydrogen peroxide, which if not degraded by catalase or glutathione peroxidase, and in the presence of transition metals, can lead to production of extremely reactive hydroxyl radicals [28, 29]. Superoxide anion radicals can also react with nitric oxide to form reactive peroxynitrite radicals [30, 31]. Hyperglycemia is also found to promote lipid peroxidation of low density lipoprotein (LDL) by a superoxidedependent pathway resulting in the generation of free radicals [32,33]. Another important source of free radicals in diabetes is the interaction of glucose with proteins leading to the formation of an Amadori product and then advanced glycation endproducts (AGEs) [34, 35]. These AGEs, via their receptors (RAGEs), inactivate enzymes and alter their structures and functions [36], promote free radical formation [37, 38], and quench and block antiproliferative effects of nitric oxide [39, 40]. By increasing intracellular oxidative stress, AGEs activate the transcription factor NF- $\mathrm{kB}$, thus promoting up-regulation of various NF$\kappa \mathrm{B}$ controlled target genes [41]. NF- $\mathrm{B}$ enhances production of nitric oxide, which is believed to be a mediator of islet beta cell damage. Considerable evidence also implicates activation of the sorbitol pathway by glucose as a component in the pathogenesis of diabetic complications, for example, in lens cataract formation or peripheral neuropathy [42-44]. Efforts to understand cataract formation have provoked various hypotheses. In the aldose reductase osmotic hypothesis, accumulation of polyols initiates lenticular osmotic changes. 
In addition, oxidative stress is linked to decreased glutathione levels and depletion of NADPH levels [45, 46]. Alternatively, increased sorbitol dehydrogenase activity is associated with altered NAD+ levels, which results in protein modification by nonenzymatic glycosylation of lens proteins [47, 48]. Mechanisms linking the changes in diabetic neuropathy and induced sorbitol pathway are not well delineated. One possible mechanism, metabolic imbalances in the neural tissues, has been implicated in impaired neurotrophism $[49,50]$, neurotransmission changes [51, 52], Schwann cell injury [53, 54], and axonopathy $[55,56]$.

\subsection{Overview of antioxidants}

While on the one hand hyperglycemia engenders free radicals, on the other hand it also impairs the endogenous antioxidant defense system in many ways during diabetes [57]. Antioxidant defense mechanisms involve both enzymatic and nonenzymatic strategies. Common antioxidants include the vitamins A, C, and E, glutathione, and the enzymes superoxide dismutase, catalase, glutathione peroxidase, and glutathione reductase. Other antioxidants include $\alpha$-lipoic acid, mixed carotenoids, coenzyme Q10, several bioflavonoids, antioxidant minerals (copper, zinc, manganese, and selenium), and the cofactors (folic acid, vitamins B1, B2, B6, B12). They work in synergy with each other and against different types of free radicals. Vitamin E suppresses the propagation of lipid peroxidation; vitamin $\mathrm{C}$, with vitamin E, inhibits hydroperoxide formation; metal complexing agents, such as penicillamine, bind transition metals involved in some reactions in lipid peroxidation [58] and inhibit Fenton and Haber- Weiss-type reactions; vitamins A and E scavenge free radicals [30, 37].

Several discrepancies observed in the activities of SOD, catalase, and glutathione peroxidase in experimentally diabetic animals. Decreased levels of glutathione and elevated concentrations of thiobarbituric acid reactants are consistently observed in diabetes [59, 60]. In addition, changes in nitric oxide and glycated proteins are also seen in diabetes.

\section{Biomarkers of lipid peroxidation}

Since the initial discoveries of Dilliard and colleagues [61], several commercial assay kits have been made available for the measurement of oxidative stress, with many new kits emerging each year. Furthermore, the discovery and utilization of F2-isoprostanes, a prostaglandin like compound, measured via gas chromotomography mass spectrometry has emerged as a substantially more reliable and valid measure of lipid peroxidation [62]. Newly developed ELISA kits for both isoprostanes as well as protein carbonyls are also now available, proving an opportunity for a more widespread use of these biomarkers. In regards to measurement of oxidative stress, due to the high reactivity and relatively short half lives (e.g., $10^{-5}, 10^{-9}$ seconds for superoxide radical and hydroxyl radical, respectively) of reactive oxygen and nitrogen species (RONS), direct measurement is extremely difficult to employ. However, direct assessment of free radical production is possible via electron spin resonance spectroscopy (ESR) involving spin traps, as well as two other less common 
techniques such as radiolysis and laser flash photolysis [63]. ESR works by recording the energy changes that occur as unpaired electrons align in response to a magnetic field [64]. Due to the high cost of such equipment and the high degree of labor associated with each direct method, the majority of free radial research related to exercise has utilized indirect methods for the assessment of resultant oxidative stress. Indirect assessment of oxidative stress involves the measurement of the more stable molecular products formed via the reaction of RONS with certain biomolecules. Common molecular products include stable metabolites (e.g., nitrate/nitrite), and/or concentrations of oxidation target products, including lipid peroxidation end products [isoprostanes, malondialdehyde (MDA), thiobarbituric acid reactive substances (TBARS), lipid hydroperoxides (LOOH), conjugated dienes (CD), oxidized low density lipoprotein (oxLDL)], oxidized proteins [protein carbonyls (PC), individual oxidized amino acids, nitrotyrosine (NT), and nucleic acids [8hydroxy-2-deoxyguanosine (8-OHdG), oxidized DNA bases (via the Comet Assay), strand breaks] [65]. Additionally, oxidative stress can be measured by observing alterations in the body's antioxidant defense system. This is typically done by measuring the redox changes in the major endogenous antioxidant glutathione, as well as circulating levels of vitamin $\mathrm{E}$, and vitamin C. Moreover, the activity of certain antioxidant enzymes [e.g., superoxide dismutase (SOD), glutathione peroxidase (GPx), catalase (CAT), glutathione reductase (GR)] can be assessed as indicators of the oxidative stress imposed on the tissue. Numerous antioxidant capacity assays also exist and include: Trolox Equivalent Antioxidant Capacity (TEAC), Total Antioxidant Status (TAS), Ferric Reducing Ability of Plasma (FRAP), Total RadicalTrapping Antioxidant Parameter (TRAP), and Oxygen Radical Absorbance Capacity (ORAC) [66].

\section{Exercise and lipid peroxidation}

\subsection{Lipid peroxidation and antioxidant status in acute exercise research}

Numerous studies have reported an increase in several lipid peroxidation markers following both maximal [67-69] and submaximal [70, 71] exercise. In opposition to these findings, a few studies have reported no increase in lipid peroxidation despite the use of similar maximal [72-74] and submaximal [75, 76] protocols. Increased lipid peroxidation seems to be a result of increased mitochondrial oxidative enyzme activation during aerobic exercise. However, studies reporting conflictiong findings for lipid peroxidation may be partially related to the timing of sampling, in addition to the trained status of the subjects or an insufficient intensity of exercise.

In response to conditions of strenuous physical work the body's antioxidant capacity may be temporarily decreased as its components are used to quench the harmful radicals produced. It appears that the antioxidant capacity may be temporarily reduced during and immediately post exercise [77, 78], after which time levels typically increase above basal conditions during the recovery period $[79,80]$. However, conflicting findings have been reported for each of the four main enzymes, with investigators noting increases in GPx [81, 82], SOD [82, 83], and CAT [70, 84, 85], as well as decreases in GPx [86], GR [81], SOD [78]. 
Furthermore, no change has also been reported for GPx [69], GR [87], SOD (Tauler et al., 2006), CAT [87] activity following exercise. Clearly, these results are mixed and likely depend on the time of sampling, as well as the duration and intensity of exercise, which has varied considerably across studies.

During low-intensity and duration protocols, antioxidant defenses appear sufficient to meet the RONS production, but as intensity and/or duration of exercise increases, these defenses are no longer adequate, potentially resulting in oxidative damage to surrounding tissues [67]. Other factors appear to impact the degree of antioxidant defenses present, including age, training status [81, 88], and dietary intake [80].

It has been shown that anaerobic exercise results in increased RONS production [89]. The mechanisms responsible for the exercise-induced increases in RONS have been suggested to be largely a function of radical generating enzymes (activated in response to ischemia followed by reperfusion) and/or phagocytic immune response following muscle damaging exercise. In the literature, there are fewer data on the markers of lipid peroxidation after anaerobic exercise. It currently remains to be elucidate whether increased RONS formation observed during anaerobic exercise represents a necessary or harmful event.

\subsection{Lipid peroxidation and antioxidant status after exercise training}

Regular physical exercise exerts numereous adaptive responses in several tissues. In the context of lipid peroxidation, repeated exposure of RONS production appears to induced to maintain the optimal health. Literature data demonstrated that regular moderate exercise is strengthening the endogenous antioxidant defense system [90, 91,92], and in some animal studies, it has decreased lipid peroxidation. On the other hand, exercise training - both endurance and interval type - appears to protects against exercise induced oxidative stress $[93,94,95]$.

\section{Exercise and diabetes}

The therapeutic use of physical exercise for diabetes treatment has been promoted since 600 B.C. before the discovery of insulin in 1922. Some investigators highlighted the interaction between this hormone and regular physical activity, with possible beneficial results in diabetes treatment [96]. Recent guidelines provide exercise recommendations for people with diabetes based on the strong and convincing epidemiologic association of aerobic exercise with lower cardiovascular disease risk in people with diabetes. The recent 2010 ADA/American College of Sports Medicine (ACSM) exercise guidelines recommend 150 minutes of weekly aerobic exercise (i.e. brisk walking or an equivalent activity with intensity $\geq 40 \% \mathrm{VO} 2 \mathrm{max}$ ); and resistance exercise of major muscle groups two to three times weekly on non-consecutive days (ACSM evidence category B, ADA B level recommendation). The ADA/ACSM guidelines also suggest adding unstructured physical activity as much as possible. Before undertaking exercise more intense than brisk walking, sedentary people with T2D should be evaluated by a physician and an exercise trainer [19]. 
Exercise has been shown to promote beneficial effects on insulin resistance, both in humans and in rodent models of diabetes [97, 98]. Regular physical exercise may prevent diabetes complications through beneficial effects on glycemic control, insulin sensitivity, blood pressure, lipid profile, and endothelial function. Moderate exercise training has been demonstrated to decrease the plasma glucose concentration in STZ-induced diabetic rats [99]. Hypoglycemic effect of exercise can be explained by exercise induced increase in uptake of glucose of muscle which induces increase of GLUT 4 expression and translocation from intracellular pool $[100,101]$. Increase in glucose uptake seems to be related to the increased number of GLUT-4 glucose transporters, although the type of training, strain, age and sex of the animals seem to affect significantly the expression of GLUT-4 [100]. On the other hand, Etgen et al. [101] found that exercise training of normal rats results in an elevated maximal insulin-stimulated hindlimb glucose uptake. They suggested that this increase was only partially explained by an increase in total muscle GLUT-4 protein content. A recent study showed that physical training improves in vivo mitochondrial function concomitantly with increased insulin sensitivity in type 2 diabetes patients and control participants [102].

\section{Exercise and chronical complications of diabetes}

\subsection{Exercise and cardiovascular disease (CVD)}

Regular exercise has beneficial effects on glucose control and cardiovascular disease (CVD) risk factors. Exercise improves and maintains cardiorespiratory fitness, muscular strength, endurance, and body composition [103]. Exercise has a favorable effect on cardiovascular risk factors. In particular, it has specific beneficial effects on the reduction of hypertension, hyperlipidemia, and obesity and the improvement in blood lipid profile [104] even when combined with a rigorous calorie-restricted diet in obese patients with T2DM [105].

The effects of exercise training on abnormal vascular structure and function (including endothelial dysfunction and vascular distensibility) associated with diabetes are yet to be fully understood [106].

Oxidative stress has been suggested to play a role in either the primary or secondary etiology of both congestive heart failure (CHF) and coronary arter disease (CAD) $[107,108]$ evident by increased oxidative stress biomarkers and/or decreased antioxidant defenses at rest in diseased compared to healthy controls [109]. Increased TBARS [110, 111] and GSSG [110] have been reported following submaximal aerobic exercise in type 1 diabetic subjects. In regards to maximal exercise, direct production of RONS via electron spin resonance spectroscopy has been reported following a graded exercise testing. However, it is important to note that significance was only achieved when data for both type 1 diabetic and healthy control subjects were pooled [112]. Despite the observation of increased levels of exercise-induced oxidative stress biomarkers in studies involving type 1 diabetics, when compared to healthy individuals, the relative magnitude of increase does not differ; rather the group differences at rest are merely maintained during the post exercise period. Other investigators have reported no changes in MDA [112], total glutathione (TGSH), antioxidant 
enzyme activity or circulating antioxidants [111] in response to acute exercise in type 1 diabetics .

\subsection{Diabetic nephropathy}

Diabetic nephropathy is the most feared complication of diabetes, due to its substantial comorbidity (need for dialysis, blindness, amputations, etc.), cost, and mortality (the annual mortality rate of diabetic patients with kidney failure on dialysis is about 25\%) [113, 114]. The major determinants of kidney disease and its progression to end-stage kidney failure in diabetes are uncontrolled blood glucose, blood pressure and albuminuria [115, 116].

Diabetic nephropathy is an important complication of diabetes since it can lead to end-stage renal failure and also it is a risk factor of cardiovascular disease. The clinical problems caused by diabetic nephropathy are proteinuria and decreased renal function. Diabetic nephropathy is defined by proteinuria $>500 \mathrm{mg}$ in 24 hours in the setting of diabetes, but this is preceded by lower degrees of proteinuria, or "microalbuminuria.". Microalbuminuria is defined as albumin excretion of 30-299 mg/24 hours [11]. Without intervention, diabetic patients with microalbuminuria typically progress to proteinuria and overt diabetic nephropathy.

In vitro studies indicate that hyperglycemia directly enhances oxidative stress in cultured endothelial and mesangial cells, which are targets for injury in diabetes [38, 117]. Several different antioxidants, including vitamin E (VE), vitamin C (VC), taurine, and $\alpha$-lipoic acid (LA), have been reported to ameliorate renal injury in experimental diabetes [118-120]. In human diabetes, there is evidence that short-term (3 to $4 \mathrm{mo}$ ), high-dose (1600 to $1800 \mathrm{IU} / \mathrm{d}$ ) VE supplementation reduces proteinuria in type 1 and 2 patients with overt nephropathy and decreases hyperfiltration in type 1 patients without overt nephropathy [121].

Urinary albumin excretion occurs normally after exercise [122, 123]. Post-exercise urinary albumin excretion is explained by increased glomerular capillary membrane permeability as a result of increased filtration pressure with increased filtered protein load, and decreased tubular absorption [122, 123]. In normal subjects, proteinuria is better related to exercise intensity and lactate production than to exercise duration [124], it diminishes after $1 \mathrm{~h} \mathrm{[125]}$ and returns to baseline within $24 \mathrm{~h}$ [122]. In diabetes mellitus, the kidneys are more sensitive to the haemodynamic exercise stress [122]. Under exercise, patients with Type 1 diabetes show a partial depletion of negative charges on the glomerular capillary wall [126] that permits the increase of urinary albumin excretion [127]. Reports indicate that urinary albumin excretion increases after exercise, without correlation with glycaemic control, renal function, disease evolution or resting urinary albumin excretion [128, 129]. In contrast, postexercise albuminuria has been found to be associated with $\mathrm{HbA1c}[127,129]$.

On the other hand, recent data demonstrated that exercise might protect the diabetic renal function [130]. Kutlu et al. demonstrated that moderate exercise with combined vitamin E and $C$ supplement was strengthen the antioxidant defense system and reduced the lipid peroxidation in STZ-induced diabetic rat kidney [131]. 


\subsection{Diabetic retinopathy}

Diabetic retinopathy may be the most common microvascular complication of diabetes. The risk of developing diabetic retinopathy or other microvascular complications of diabetes depends on both the duration and the severity of hyperglycemia. Development of diabetic retinopathy in patients with type 2 diabetes was found to be related to both severity of hyperglycemia and presence of hypertension in the U.K Prospective Diabetes Study (UKPDS) [132] and most patients with type 1 diabetes develop evidence of retinopathy within 20 years of diagnosis [133]. Retinopathy may begin to develop as early as 7 years before the diagnosis of diabetes in patients with type 2 diabetes [134]. There are several proposed pathological mechanisms by which diabetes may lead to development of retinopathy.

Oxidative stress may also play an important role in cellular injury from hyperglycemia. High glucose levels can stimulate free radical production and reactive oxygen species formation. Animal studies have suggested that treatment with antioxidants, such as vitamin E, may attenuate some vascular dysfunction associated with diabetes, but treatment with antioxidants has not yet been shown to alter the development or progression of retinopathy or other microvascular complications of diabetes [11].

\subsection{Diabetic neuropathy}

Diabetic polyneuropathy affects $30 \%$ of the hospital-based population and $20 \%$ of community based samples of diabetic patients [135]. There is a growing body of evidence to support the notion that oxidative stress is the biochemical trigger for nerve dysfunction. Various disturbances such as reduced endoneurial blood flow, altered electroconductive properties of the myelin sheath, impaired incorporation of acetate and glucose into the neuron cells should also be mentioned in diabetic condition. It has been shown [136] that superoxide dismutase activity is decreased in nerves from streptozotocin-induced diabetic rats. Glutathione content and glutathione peroxidase activity are also diminished in sciatic nerves from diabetic rats $[137,138]$. Nerves of diabetic rats show lower amounts of vitamin E compared to control animals [139]. Lipid peroxidation products such as malondialdehydes or conjugated dienes are elevated in diabetic sciatic nerves [136, 139]. Treatment of diabetic rats with insulin or antioxidants is associated with improved nerve function [51, 140].

Sensory, visual and auditory neural conduction deficits are well documented both in diabetic animals and human studies. As an early marker of visual system deficits observed in diabetic state, visual evoked potential (VEP) latencies were measured in STZ-induced diabetic rats in our laboratories. The results of the previous studies were demonstrated that visual evoked potential (VEP) latencies were prolonged in STZ-induced diabetic rats whereas the latencies were restored by moderate physical exercise [60, 141, 142]. The VEP alterations were found to be accompanied with the increased TBARS concentration in the brain tissues of the diabetic rats. 
The impact of diabetes on nervous system is complex and poorly elucidated. The brain is particularly vulnerable to oxidative damage because of its high rate of oxygen consumption, intense production of reactive radicals, and high levels of transition metals, such as iron, that catalyze the production of reactive radicals [143]. Moreover, neuronal membranes are rich in poly unsaturated fatty acids, which are a source of lipid peroxidation [37]. Free radicals are formed disproportionately in diabetes by glucose oxidation, non-enzymatic glycation of proteins, and the subsequent oxidative degradation of glycated proteins. Abnormally high levels of free radicals and the simultaneous decline of antioxidant defense mechanisms can lead to damage of cellular organelles and enzymes, increased lipid peroxidation, and development of insulin resistance. These consequences of oxidative stress can promote the development of complications of diabetes mellitus [143].

Previous experimental studies demonstrated that diabetes resulted increased lipid peroxidation and decreased antioxidant enzymes in several brain regions such as hypocampus, striatum and cerebral cortex as well as in whole brain tissue homogenates [59]. The lipids oxidation in the CNS usually demonstrates different concentrations at different regions of the brain, and it can be attributed to regional differences in the $\mathrm{O} 2$ consumption [144, 145].

Nervous system complications of diabetes mellitus can become one of the most debilitating complications and affect sensitive and cognitive functions that modulates memory function, resulting in significant functional impairment and dementia. Oxidative stress forms the foundation for the induction of multiple cellular pathways that can ultimately lead to both the onset and subsequent complications of DM [146]. Defects in hippocampal synaptic plasticity and transmission resulting in impairment of learning and memory is one the central nervous system complications of diabetes mellitus [147, 148]. Increasing evidence in both experimental and clinical studies suggests that oxidative stress plays a central role in the onset and subsequent complications of diabetes mellitus [149].

Physical exercise has been demonstrated to induce several neurobiological changes in the brain and to prevent diabetes-induced cognitive decline. The neurobiological changes induced by physical exercise have been demonstrated to facilitate the acquisition of a spatial memory task in rats. Exercise has also been demonstrated to increase the cognitive function both in healthy and diabetic people [150, 151, 152]. However, intense exercise has been shown to impaired the cognitive function in murine model that was prevented by vitamin $\mathrm{C}$ and E supplementation [153].

\section{Conclusion}

Literature results emphasize the beneficial role of physical exercise in the promotion of in diabetic complications probably by decreasing hyperglicemia, increasing insulin sensitivity and enhancing antioxidant status of the several systems. The type, duration and the intensity of the exercise as well as the degree of the diabetic complications should be determined before the exercise prescription in diabetic person. For future research, the effects of the different exercise protocols for maintaining the optimum health and 
stimulating the cellular processes for decreasing the hyperglicemia-induced complications in diabetes in children and older people remains to be explored.

\section{Author details}

Yaşar Gül Özkaya

School of Physical Education and Sports, Akdeniz University, Antalya, Turkey

\section{References}

[1] World Health Organization. Media Centre. Diabetes. http://www.who.int/mediacentre/factsheets/fs312/en/index.html (accessed 12 May 2008).

[2] Maritim, A. C., R. A. Sanders \& J. B. Watkins. Diabetes, oxidative stress, and antioxidants: A review. Journal of Biochemical and Molecular Toxicology. 2003;17:2438.

[3] Paik SG, Blue ML, Fleischer N, Shin SI. Diabetes susceptibility of balb/cbom mice treated with streptozotocin - inhibition by lethal irradiation and restoration by splenic lymphocytes. Diabetes. 1982;31(9):808-15.

[4] Sandler S, Andersson AK, Barbu A, Hellerstrom C, Holstad M, Karlsson E, Sandberg JO, Strandell E, Saldeen J, Sternesjo J, Tillmar L, Eizirik DL, Flodstrom M \& Welsh N. Novel experimental strategies to prevent the development of type 1 diabetes mellitus. Upsala Journal of Medical Sciences. 2000;105(2):17-34.

[5] Shewad Y, Tirth S \& Bhonde RR. Pancreatic islet-cell viability, functionality and oxidative status remain unaffected at pharmacological concentrations of commonly used antibiotics in vitro. Journal of Biosciences. 2001;26(3):349-355.

[6] American Diabetes Association (ADA) Position Statement (2010). Diagnosis and Classification of Diabetes Mellitus. Diabetes Care.2010;33(Supplement 1): S62-S69.

[7] de Lemos ET, Pinto Ri Oliveira J, Garrido P, Sereno J, Mascarenhas-Melo F, Pascoa Pinheiro J, Teixeira F \& Reis F. (2011). Differential effects of acute (extenuating) and chronic (training) exercise on inflammation and oxidative stress status in an animal model of Type 2 diabetes mellitus. Mediators of Inflammation. 2011;253061:1-8.

[8] P'erez-Matute P, Zulet MA \& Mart'inez JA (2009). Reactive species and diabetes: Counteracting oxidative stress to improve health. Current Opinion in Pharmacology. 2009;9(6):771-779.

[9] Brunner Y, Schvartz D, Priego-Capote F, Cout'e Y \& Sanchez JC (2009). Glucotoxicity and pancreatic proteomics. Journal of Proteomics.2009;71(6):576-591.

[10] Donath MY, Schumann DM, Faulenbach M, Ellingsgaard H, Perren A \& Ehses JA. Islet inflammation in type 2 diabetes: from metabolic stress to therapy. Diabetes Care. 2008;31(Supplement 2):S161-164.

[11] Fowler MJ. Microvascular and Macrovascular Complications of Diabetes. Clinical Diabetes. 2008;26(2):77-82. 
[12] Ballas LM, Jirousek MR, Umeda F, Nawata H, King GL. Vitamin E prevents diabetes induced abnormal retinal blood flow via the diacylglycerolprotein kinase C pathway. American Journal of Physiology. 1995;269: E239- E246.

[13] Watkins PJ. Retinopathy. BMJ.2003;326:924-926.

[14] Gross JL, de Azevedo MJ, Silveiro SP, Canani LH, Caramori ML \& Zelmanovitz T. Diabetic nephropathy: diagnosis, prevention, and treatment. Diabetes Care. 2005;28:164-176.

[15] Chaturvedi N, Bandinelli S, Mangili R, Penno G, Rottiers RE.\& Fuller JH. Microalbuminuria in type 1 diabetes: rates, risk factors and glycemic threshold. Kidney International. 2001;60: 219- 227.

[16] Adler AI, Stevens RJ, Manley SE, Bilous RW, Cull CA \& Holman RR (2003). Development and progression of nephropathy in type 2 diabetes: the United Kingdom Prospective Diabetes Study (UKPDS 64). Kidney International. 2003;63:225-232.

[17] Kunisaki M, Bursell SE, Clermont AC, Ishii H, Ballas LM, Jirousek MR, Umeda F, Nawata H, King GL. Vitamin E prevents diabetes-induced abnormal retinal blood flow via the diacylglycerol-protein kinase C pathway. American Journal of PhysiologyEndocrinology and Metabolism. 1995;269(2):E239-E46.

[18] Sigal RJ, Kenny GP, Wasserman DH, Castaneda-Sceppa C \& White RD. Physical activity/exercise and type 2 diabetes: a consensus statement from the American Diabetes Association. Diabetes Care. 2006;29(6):1433-8.

[19] Colberg SR, Albright AL, Blissmer BJ, Braun B, Chasan-Taber L, Fernhall B, Regensteiner JG, Rubin RR \& Sigal RJ. Exercise and Type 2 Diabetes ACSM ADA Joint Position Statement. Medicine \& Science In Sports \& Exercise. 2010;42(12): 2282-2303.

[20] Marrero DG. Time to get moving: helping patients with diabetes adopt exercise as part of a healthy lifestyle. Clinical Diabetes. 2005;23 (4):154-159.

[21] Hevener AL, Reichart D \& Olefsky J. Exercise and thiazolidinedione therapy normalize insulin action in the obese Zucker fatty rat. Diabetes. 2000;49(12):2154- 2159.

[22] Pold R, Jensen LS, Jessen $N$ et al. Long-term AICAR administration and exercise prevents diabetes in ZDF rats. Diabetes. 2005;54(4):928-934.

[23] Klein S, Sheard NF, Pi-Sunyer X, Daly A, Wylie-Rosett J, Kulkarni K \& Clark NG. American Diabetes Association, American Association for the Study of Obesity, American Society for Clinical Nutrition: Weight management through lifestyle modification for the prevention and management of type 2 diabetes: rationale and strategies. Diabetes Care.2004;27:2067-2073.

[24] Boule N, Haddad E, Kenny G, Wells G \& Sigal R. Effects of exercise on glycemic control and body mass in type 2 diabetes: a meta-analysis of controlled clinical trials. JAMA.2001;286:1218 1227.

[25] de Lemos ET, Reis F, Baptista S. et al. Exercise training is associated with improved levels of C-reactive protein and adiponectin in ZDF (type 2) diabetic rats. Medical Science Monitor. 2007;13(8):BR168-BR174. 
[26] Connor TJ, Brewer C, Kelly JP, Harkin A. Acute stress suppresses pro-inflammatory cytokines TNF-alpha and IL-1 beta independent of a catecholamine-driven increase in IL-10 production. Journal of Neuroimmunology. 2005;159(1-2):119-28.

[27] Giraldo E, Garcia JJ, Hinchado MD, Ortega E. Exercise Intensity-Dependent Changes in the Inflammatory Response in Sedentary Women: Role of Neuroendocrine Parameters in the Neutrophil Phagocytic Process and the Pro-/Anti-Inflammatory Cytokine Balance. Neuroimmunomodulation. 2009;16(4):237-44.

[28] Jiang ZY, Woollard ACS, Wolff SP. Hydrogen-peroxide production during experimental protein glycation. Febs Letters. 1990;268(1):69-71.

[29] Wolff SP, Dean RT. Glucose autoxidation and protein modification - the potential role of autoxidative glycosylation in diabetes. Biochemical Journal. 1987;245(1):243-50.

[30] Halliwell B, Gutteridge JMC. Role of free-radicals and catalytic metal-ions in humandisease - an overview. Methods in Enzymology. 1990;186:1-85.

[31] Hogg N, Kalyanaraman B, Joseph J, Struck A, Parthasarathy S. Inhibition of lowdensity-lipoprotein oxidation by nitric-oxide - potential role in atherogenesis. Febs Letters. 1993;334(2):170-4.

[32] Tsai EC, Hirsch IB, Brunzell JD, Chait A. Reduced plasma peroxyl radical trapping capacity and increased susceptibility of LDL to oxidation in poorly controlled IDDM. Diabetes. 1994;43(8):1010-4.

[33] Kawamura M, Heinecke JW, Chait A. Pathophysiological concentrations of glucose promote oxidative modfication of low-density-lipoprotein by a superoxide-dependent pathway. Journal of Clinical Investigation. 1994;94(2):771-8.

[34] Hori O, Yan SD, Ogawa S, Kuwabara K, Matsumoto M, Stern D, et al. The receptor for advanced glycation end-products has a central role in mediating the effects of advanced glycation end-products on the development of vascular disease in diabetes mellitus. Nephrology Dialysis Transplantation. 1996;11:13-6.

[35] Mullarkey CJ, Edelstein D, Brownlee M. Free-radical generation by early glycation products - a mechanism for accelerated atherogenesis in diabetes. Biochemical and Biophysical Research Communications. 1990;173(3):932-9.

[36] McCarthy AD, Etcheverry SB, Cortizo AM. Effect of advanced glycation endproducts on the secretion of insulin-like growth factor-I and its binding proteins: role in osteoblast development. Acta Diabetologica. 2001;38(3):113-22.

[37] Baynes JW. Role of oxidative stress in development of complications in diabetes. Diabetes. 1991;40(4):405-12.

[38] Baynes JW, Thorpe SR. Role of oxidative stress in diabetic complications - A new perspective on an old paradigm. Diabetes. 1999;48(1):1-9.

[39] Vlassara H. Recent progress in advanced glycation end products and diabetic complications. Diabetes. 1997;46:S19-S25.

[40] Wautier JL, Wautier MP, Schmidt AM, Anderson GM, Hori O, Zoukourian C, et al. Advanced glycation end-products (ages) on the surface of diabetic erythrocytes bind to the vessel wall via a specific receptor inducing oxidant stress in the vasculature - a link 
between surface-associated ages and diabetic complications. Proceedings of the National Academy of Sciences of the United States of America. 1994;91(16):7742-6.

[41] Mohamed AK, Bierhaus A, Schiekofer S, Tritschler H, Ziegler R, Nawroth PP. The role of oxidative stress and NF-kappa B activation in late diabetic complications. Biofactors. 1999;10(2-3):157-67.

[42] Kador PF, Kinoshita JH. Diabetic and galactosemic cataracts. Ciba Foundation Symposia. 1984;106:110-31.

[43] Greene DA, Sima AAF, Stevens MJ, Feldman EL, Lattimer SA. Complications neuropathy, pathogenetic considerations. Diabetes Care. 1992;15(12):1902-25.

[44] Obrosova I, Faller A, Burgan J, Ostrow E, Williamson JR. Glycolytic pathway, redox state of $\mathrm{NAD}(\mathrm{P})$-couples and energy metabolism in lens in galactose-fed rats: Effect of an aldose reductase inhibitor. Current Eye Research. 1997;16(1):34-43.

[45] Gonzalez AM, Sochor M, Hothersall JS, Mclean P. Effect of aldose reductase inhibitor (sorbinil) on integration of polyol pathway, pentose-phosphate pathway, and glycolytic route in diabetic rat lens. Diabetes. 1986;35(11):1200-5.

[46] Cheng HM, Gonzalez RG. The effect of high glucose and oxidative stress on lens metabolism, aldose reductase, and senile cataractogenesis. Metabolism-Clinical and Experimental. 1986;35(4):10-4.

[47] Yano M, Matsuda S, Bando Y, Shima K. Lens protein glycation and the subsequent degree of opacity in streptozotocin-diabetic rats. Diabetes Research and Clinical Practice. 1989;7(4):259-62.

[48] Ramalho JS, Marques C, Pereira PC \& Mota MC. Role of glycation in human lens protein structure change. European Journal of Ophthalmology.1996;6(2):155-161.

[49] Mizisin AP, Bache M, distefano PS, Acheson A, Lindsay RM, Calcutt NA. BDNF attenuates functional and structural disorders in nerves of galactose-fed rats. Journal of Neuropathology and Experimental Neurology. 1997;56(12):1290-301.

[50] Hounsom L, Horrobin DF, Tritschler H, Corder R, Tomlinson DR. A lipoic acid gamma linolenic acid conjugate is effective against multiple indices of experimental diabetic neuropathy. Diabetologia. 1998;41(7):839-43.

[51] Stevens MJ, Obrosova I, Cao XH, Van Huysen C, Greene DA. Effects of DL-alpha-lipoic acid on peripheral nerve conduction, blood flow, energy metabolism, and oxidative stress in experimental diabetic neuropathy. Diabetes. 2000;49(6):1006-15.

[52] Ralevic V, Belai A, Burnstock G. Effects of streptozotocin-diabetes on sympatheticnerve, endothelial and smooth-muscle function in the rat mesenteric arterial bed. European Journal of Pharmacology. 1995;286(2):193-9.

[53] Mizisin AP, Kalichman MW, Bache M, Dines KC, distefano PS. NT-3 attenuates functional and structural disorders in sensory nerves of galactose-fed rats. Journal of Neuropathology and Experimental Neurology. 1998;57(9):803-13.

[54] Kalichman MW, Powell HC, Mizisin AP. Reactive, degenerative, and proliferative Schwann cell responses in experimental galactose and human diabetic neuropathy. Acta Neuropathologica. 1998;95(1):47-56. 
[55] Chokroverty S, Seiden D, Navidad P \& Cody R. Distal axonopathy in streptozotocin diabetes in rats. Experientia. 1988;44(5):444-446.

[56] Fernyhough P, Gallagher A, Averill SA, Priestley JV, Hounsom L, Patel J, et al. Aberrant neurofilament phosphorylation in sensory neurons of rats with diabetic neuropathy. Diabetes. 1999;48(4):881-9.

[57] Saxena AK, Srivastava P, Kale RK, Baquer NZ. Impaired antioxidant status in diabetic rat-liver - effect of vanadate. Biochemical Pharmacology. 1993;45(3):539-42.

[58] Feher J, Cosmos G \& Vereckei A. Free Radical Reactions in Medicine. Berlin:SpringerVerlag;1987.

[59] Ozkaya YG, Agar A, Yargicoglu P, Hacioglu G, Bilmen-Sarikcioglu S, Ozen I, et al. The effect of exercise on brain antioxidant status of diabetic rats. Diabetes \& Metabolism. 2002;28(5):377-84.

[60] Ozkaya YG, Hacioglu G, Kucukatay V, Yargicoglu P, Agar A. The Effect of Chronic $\mathrm{N}(\mathrm{G})$-Nitro-L-arginine Methyl Ester (L-NAME) Administration on Visual Evoked Potentials and Oxidative Stress in Streptozotocin Induced Diabetic Rats. Journal of Neurological Sciences-Turkish. 2011;28(2):132-41.

[61] Dillard CJ, Litov RE, Savin WM, Dumelin EE, Tappel AL. Effects of exercise, vitamin-E, and ozone on pulmonary-function and lipid peroxidation. Journal of Applied Physiology. 1978;45(6):927-32.

[62] Morrow JD, Roberts LJ. Mass spectrometric quantification of F-2-isoprostanes in biological fluids and tissues as measure of oxidant stress. Oxidants and Antioxidants, $\mathrm{Pt}$ B. 1999;300:3-12.

[63] Knight JA. Free Radicals, antioxidants, aging, and disease. Washington: American Association for Clinical Chemistry Press, 1999.

[64] Halliwell B, Cross CE. Oxygen-derived species - their relation to human-disease and environmental-stress. Environmental Health Perspectives. 1994;102:5-12.

[65] Dalle-Donne I, Rossi R, Colombo R, Giustarini D, Milzani A. Biomarkers of oxidative damage in human disease. Clinical Chemistry. 2006;52(4):601-23.

[66] Fisher-Wellman K \& Bloomer RJ. Acute exercise and oxidative stress: a 30 year history. Dynamic Medicine. 2009;8(1):1-8.

[67] Knez WL, Jenkins DG, Coombes JS. Oxidative stress in half and full ironman triathletes. Medicine and Science in Sports and Exercise. 2007;39(2):283-8.

[68] Steinberg JG, Ba A, Bregeon F, Delliaux S, Jammes Y. Cytokine and oxidative responses to maximal cycling exercise in sedentary subjects. Medicine and Science in Sports and Exercise. 2007;39(6):964-8.

[69] Miyazaki H, Oh-ishi S, Ookawara T, Kizaki T, Toshinai K, Ha S, et al. Strenuous endurance training in humans reduces oxidative stress following exhausting exercise. European Journal of Applied Physiology. 2001;84(1-2):1-6.

[70] Nikolaidis MG, Kyparos A, Hadziioannou M, Panou N, Samaras L, Jamurtas AZ, et al. Acute exercise markedly increases blood oxidative stress in boys and girls. Applied 
Physiology Nutrition and Metabolism-Physiologie Appliquee Nutrition Et Metabolisme. 2007;32(2):197-205.

[71] Meijer EP, Goris AHC, van Dongen JLJ, Bast A, Westerterp KR. Exercise-induced oxidative stress in older adults as a function of habitual activity level. Journal of the American Geriatrics Society. 2002;50(2):349-53.

[72] Rahnama N, Gaeini AA, Hamedinia MR. Oxidative stress responses in physical education students during 8 weeks aerobic training. Journal of Sports Medicine and Physical Fitness. 2007;47(1):119-23.

[73] Silvestro A, Scopacasa F, Oliva G, de Cristofaro T, Iuliano L, Brevetti G. Vitamin C prevents endothelial dysfunction induced by acute exercise in patients with intermittent claudication. Atherosclerosis. 2002;165(2):277-83.

[74] Gaeini AA, Rahnama N, Hamedinia MR. Effects of vitamin E supplementation on oxidative stress at rest and after exercise to exhaustion in athletic students. Journal of Sports Medicine and Physical Fitness. 2006;46(3):458-61.

[75] Morillas-Ruiz J, Zafrilla P, Almar M, Cuevas M, Lopez FJ, Abellan P, et al. The effects of an antioxidant-supplemented beverage on exercise-induced oxidative stress: results from a placebo-controlled double-blind study in cyclists. European Journal of Applied Physiology. 2005;95(5-6):543-9.

[76] Goldfarb AH, Patrick SW, Bryer S, You TJ. Vitamin C supplementation affects oxidative-stress blood markers in response to a 30-minute run at $75 \% \mathrm{VO} 2 \mathrm{max}$. International Journal of Sport Nutrition and Exercise Metabolism. 2005;15(3):279-90.

[77] Di Massimo C, Scarpelli P, Tozzi-Ciancarelli MG. Possible involvement of oxidative stress in exercise-mediated platelet activation. Clinical Hemorheology and Microcirculation. 2004;30(3-4):313-6.

[78] Tozzi-Ciancarelli MG, Penco M, Di Massimo C. Influence of acute exercise on human platelet responsiveness: possible involvement of exercise-induced oxidative stress. European Journal of Applied Physiology. 2002;86(3):266-72.

[79] Alessio HM, Hagerman AE, Fulkerson BK, Ambrose J, Rice RE, Wiley RL. Generation of reactive oxygen species after exhaustive aerobic and isometric exercise. Medicine and Science in Sports and Exercise. 2000;32(9):1576-81.

[80] Watson TA, Callister R, Taylor RD, Sibbritt DW, macdonald-Wicks LK, Garg ML. Antioxidant restriction and oxidative stress in short-duration exhaustive exercise. Medicine and Science in Sports and Exercise. 2005;37(1):63-71.

[81] Elosua R, Molina L, Fito M, Arquer A, Sanchez-Quesada JL, Covas MI, et al. Response of oxidative stress biomarkers to a 16-week aerobic physical activity program, and to acute physical activity, in healthy young men and women. Atherosclerosis. 2008;197(2):967.

[82] Buczynski A, Kedziora J, Tkaczewski W, Wachowicz B. Effect of submaximal physical exercise on antioxıdative protection of human blood-platelets. International Journal of Sports Medicine. 1991;12(1):52-4. 
[83] Chen MF, Hsu HC, Lee YT. Effects of acute exercise on the changes of lipid profiles and peroxides, prostanoids, and platelet activation in hypercholesterolemic patients before and after treatment. Prostaglandins. 1994;48(3):157-74.

[84] Michailidis Y, Jamurtas AZ, Nikolaidis MG, Fatouros IG, Koutedakis Y, Papassotiriou I, et al. Sampling time is crucial for measurement of aerobic exercise-induced oxidative stress. Medicine and Science in Sports and Exercise. 2007;39(7):1107-13.

[85] Vider J, Lehtmaa J, Kullisaar T, Vihalemm T, Zilmer K, Kairane C, Landor A, Karu T \&, Zilmer M. Acute immune response in respect to exercise-induced oxidative stress. Pathophysiology.2001;7(4):263-270.

[86] Akova B, Surmen-Gur E, Gur H, Dirican M, Sarandol E, Kucukoglu S. Exercise-induced oxidative stress and muscle performance in healthy women: role of vitamin $\mathrm{E}$ supplementation and endogenous oestradiol. European Journal of Applied Physiology. 2001;84(1-2):141-7.

[87] Tauler P, Aguilo A, Gimeno I, Fuentespina E, Tur JA, Pons A. Response of blood cell antioxidant enzyme defences to antioxidant diet supplementation and to intense exercise. European Journal of Nutrition. 2006;45(4):187-95.

[88] Fatouros IG, Jamurtas AZ, Villiotou V, Pouliopoulou S, Fotinakis P, Taxildaris K, et al. Oxidative stress responses in older men during endurance training and detraining. Medicine and Science in Sports and Exercise. 2004;36(12):2065-72.

[89] Guzel NA, Hazar S, Erbas D. Effects of different resistance exercise protocols on nitric oxide, lipid peroxidation and creatine kinase activity in sedentary males. Journal of Sports Science and Medicine. 2007;6(4):417-22.

[90] Chung HY, Cesari M, Anton S, Marzetti E, Giovannini S, Seo AY, et al. Molecular inflammation: Underpinnings of aging and age-related diseases. Ageing Research Reviews. 2009;8(1):18-30.

[91] Radak Z, Chung HY, Koltai E, Taylor AW \& Goto S. Exercise, oxidative stress and hormesis. Ageing Research Reviews. 2008;7(1):34-42.

[92] Gocmen AY, Ozkaya YG, Yazar H, Agar A, Gunaydin I \& Gumuslu S. (2011b). Effect of exercise on paraoxonase- 1 activity and lipid peroxidation in diabetes. Bozok Medical Journal. 2011;1(2):13-21.

[93] Atalay M, Marnila P, Lilius EM, Hanninen O, Sen CK. Glutathione-dependent modulation of exhausting exercise induced changes in neutrophil function of rats. European Journal of Applied Physiology and Occupational Physiology. 1996;74(4):3427.

[94] Atalay M, Seene T, Hanninen O, Sen CK. Skeletal muscle and heart antioxidant defences in response to sprint training. Acta Physiologica Scandinavica. 1996;158(2):12934.

[95] Powers SK, Ji LL, Leeuwenburgh C. Exercise training-induced alterations in skeletal muscle antioxidant capacity: a brief review. Medicine and Science in Sports and Exercise. 1999;31(7):987-97. 
[96] Steppel TH \& Horton ES. (2005). Exercise in patients with diabetes mellitus. In: Kahn CR, Weir GC, King GL, Jacobson AM, Moses AC, Smith RJ, Editors: Joslins' Diabetes Mellitus. Philadelphia: Lippincott Williams and Wilkins, 2005. pp: 649-658.

[97] Hughes VA, Fiatrone MA, Fielding RA, Kahn BB, Ferrara CM, Shepherd P, Fisher EC, Wolfe RR, Elahi D \& Evans WJ. Exercise increases muscle GLUT-4 levels and insulin action in subjects with impaired glucose tolerance. American Journal of Physiology.1993;264:E855-E862.

[98] Cox JH, Cortright RN, Dohm GL, Houmard JA. Effect of aging on response to exercise training in humans: skeletal muscle GLUT-4 and insulin sensitivity. Journal of Applied Physiology. 1999;86(6):2019-25.

[99] Giacca A, Groenewoud Y, Tsui E, McClean P, Zinman B. Glucose production, utilization, and cycling in response to moderate exercise in obese subjects with type 2 diabetes and mild hyperglycemia. Diabetes. 1998 Nov;47(11):1763-70.

[100] Kainulainen H, Komulainen J, Joost HG, Vihko V. Dissociation of the effects of training on oxidative-metabolism, glucose-utilization and GLUT4 levels in skeletalmuscle of streptozotocin-diabetic rats. Pflugers Archiv-European Journal of Physiology. 1994;427(5-6):444-9.

[101] Etgen GJ, Brozinick JT, Kang HY, Ivy JL. Effects of exercise training on skeletal-muscle glucose-uptake and transport. American Journal of Physiology. 1993;264(3):C727-C33.

[102] Wohaieb SA, Godin DV. Alterations in free-radical tissue-defense mechanisms in streptozocin-induced diabetes in rat - effects of insulin-treatment. Diabetes. 1987;36(9):1014-8.

[103] Marwick TH, Hordern MD, Miller T, Chyun DA, Bertoni AG, Blumenthal RS, et al. Exercise Training for Type 2 Diabetes Mellitus Impact on Cardiovascular Risk A Scientific Statement From the American Heart Association. Circulation. 2009;119(25):3244-62.

[104] Wilmore JH, Green JS, Stanforth PR, Gagnon J, Rankinen T, Leon AS, et al. Relationship of changes in maximal and submaximal aerobic fitness to changes in cardiovascular disease and non-insulin-dependent diabetes mellitus risk factors with endurance training: The Heritage Family Study. Metabolism-Clinical and Experimental. 2001;50(11):1255-63.

[105] Pi-Sunyer, X., Blackburn, G., Brancati, F.L., et al. (2007). Look AHEAD Research Group. Reduction in weight and cardiovascular disease risk factors in individuals with type 2 diabetes: one-year results of the Look AHEAD trial. Diabetes Care. Volume 30, pp:1374-1383.

[106] Simpson SH, Corabian P, Jacobs P, Johnson JA. The cost of major comorbidity in people with diabetes mellitus. Canadian Medical Association Journal. 2003;168(13):1661-7.

[107] Fisher-Wellman K, Bell HK, Bloomer RJ. Oxidative stress and antioxidant defense mechanisms linked to exercise during cardiopulmonary and metabolic disorders. Oxidative Medicine and Cellular Longevity. 2009;2(1):43-51. 
[108] Soccio M, Toniato E, Evangelista V, Carluccio M, De Caterina R. Oxidative stress and cardiovascular risk: the role of vascular $\mathrm{NAD}(\mathrm{P}) \mathrm{H}$ oxidase and its genetic variants. European Journal of Clinical Investigation. 2005;35(5):305-14.

[109] Tsutsui H. Oxidative stress in heart failure: The role of mitochondria. Internal Medicine. 2001;40(12):1177-82.

[110] Laaksonen DE, Uusitupa M, Atalay M, Hanninen O, Niskanen L, Sen CK. Increased resting and exercise-induced oxidative stress in young IDDM men. Diabetes Care. 1996;19(6):569-74.

[111] Atalay M, Laaksonen DE, Niskanen L, Uusitupa M, Hanninen O, Sen CK. Altered antioxidant enzyme defences in insulin-dependent diabetic men with increased resting and exercise-induced oxidative stress. Acta Physiologica Scandinavica.1997;161:195-201.

[112] Davison GW, George L, Jackson SK, Young IS, Davies B, Bailey DM, et al. Exercise, free radicals, and lipid peroxidation in type 1 diabetes mellitus. Free Radical Biology and Medicine. 2002;33(11):1543-51.

[113] Leehey DJ, Moinuddin I, Bast JP, Qureshi S, Jelinek CS, Cooper C, et al. Aerobic exercise in obese diabetic patients with chronic kidney disease: a randomized and controlled pilot study. Cardiovascular Diabetology. 2009;8:62.

[114] US Renal Data System: USRDS 2008 Annual Data Report Bethesda: National Institutes of Health, National Institute of Diabetes and Digestive and Kidney Diseases; 2008.

[115] Stratton IM, Cull CA, Adler AI, Matthews DR, Neil HAW, Holman RR. Additive effects of glycaemia and blood pressure exposure on risk of complications in type 2 diabetes: a prospective observational study (UKPDS 75). Diabetologia. 2006;49(8):17619.

[116] Rossing K, Christensen PK, Hovind P, Parving HH. Remission of nephrotic-range albuminuria reduces risk of end-stage renal disease and improves survival in type 2 diabetic patients. Diabetologia. 2005;48(11):2241-7.

[117] Giugliano D, Ceriello A, Paolisso G. Oxidative stress and diabetic vascular complications. Diabetes Care. 1996;19(3):257-67.

[118] Lee,EY, Lee MY, Hong SW, Choon Hee Chung CH, Hong SY. Blockade of oxidative stress by vitamin $\mathrm{C}$ ameliorates albuminuria and renal sclerosis in experimental diabetic rats. Yonsei Medical Journal. 2007; 31; 48(5): 847-855.

[119] Trachtman H, Futterweit S, Maesaka J, Ma C, Valderrama E, Fuchs A, et al. Taurine ameliorates chronic streptozocin-induced diabetic nephropathy in rats. American Journal of Physiology-Renal Fluid and Electrolyte Physiology. 1995;269(3):F429-F38.

[120] Craven PA, derubertis FR, Kagan VE, Melhem M, Studer RK. Effects of supplementation with vitamin $\mathrm{C}$ or $\mathrm{E}$ on albuminuria, glomerular TGF-beta, and glomerular size in diabetes. Journal of the American Society of Nephrology. 1997;8(9):1405-14.

[121] Bursell SE, Clermont AC, Aiello LP, Aiello LM, Schlossman DK, Feener EP, et al. Highdose vitamin $\mathrm{E}$ supplementation normalizes retinal blood flow and creatinine clearance in patients with type 1 Diabetes. Diabetes Care. 1999;22(8):1245-51. 
[122] Poortmans JR, Labilloy D. The influence of work intensity on postexercise proteinuria. European Journal of Applied Physiology and Occupational Physiology. 1988;57(2):2603.

[123] Heathcote KL, Wilson MP, Quest DW, Wilson TW. Prevalence and duration of exercise induced albuminuria in healthy people. Clinical and Investigative Medicine. 2009;32(4):E261-E5.

[124] Poortmans JR, Geudvert C, Schorokoff K, deplaen P. Postexercise proteinuria in childhood and adolescence. International Journal of Sports Medicine. 1996;17(6):448-51.

[125] Poortmans JR, Vanderstraeten J. Kidney-function during exercise in healthy and diseased humans - an update. Sports Medicine. 1994;18(6):419-37.

[126] Ala-Houhala I. Effects of exercise on glomerular passage of macromolecules in patients with diabetic nephropathy and in healthy subjects. Scandinavian Journal of Clinical and Laboratory Investigation.1990;50:27-33.

[127] Huttunen NP, Kaar ML, Puukka R, Akerblom HK. Exercise-induced proteinuria in children and adolescents with type-1 (insulin dependent) diabetes. Diabetologia. 1981;21(5):495-7.

[128] Feldtrasmussen B, Baker L, Deckert T. Exercise as a provocative test in early renaldisease in type-1 (insulin-dependent) diabetes - albuminuric, systemic and renal hemodynamic-responses. Diabetologia. 1985;28(7):389-96.

[129] Kruger M, Gordjani N, Burghard R. Postexercise albuminuria in children with different duration of type-1 diabetes mellitus. Pediatric Nephrology. 1996;10(5):594-7.

[130] Kurdak H, Sandikci S, Ergen N, Dogan A, Kurdak SS. The effects of regular aerobic exercise on renal functions in streptozotocin induced diabetic rats. Journal of Sports Science and Medicine. 2010;9(2):294-9.

[131] Kutlu M, Naziroglu M, Simsek H, Yilmaz T, Kukner AA. Moderate exercise combined with dietary vitamins $\mathrm{C}$ and $\mathrm{E}$ counteracts oxidative stress in the kidney and lens of streptozotocin-induced diabetic rat. International Journal for Vitamin and Nutrition Research. 2005;75(1):71-80.

[132] Turner RC, Holman RR, Cull CA, Stratton IM, Matthews DR, Frighi V, et al. Intensive blood-glucose control with sulphonylureas or insulin compared with conventional treatment and risk of complications in patients with type 2 diabetes (UKPDS 33). Lancet. 1998;352(9131):837-53.

[133] Keenan HA, Costacou T, Sun JK, Doria A, Cavellerano J, Coney J, et al. Clinical factors associated with resistance to microvascular complications in diabetic patients of extreme disease duration - The 50-year medalist study. Diabetes Care. 2007;30(8):1995-7.

[134] Fong DS, Aiello LP, Ferris FL, Klein R. Diabetic retinopathy. Diabetes Care. 2004;27(10):2540-53.

[135] Ziegler D, Sohr CGH, Nourooz-Zadeh J. Oxidative stress and antioxidant defense in relation to the severity of diabetic polyneuropathy and cardiovascular autonomic neuropathy. Diabetes Care. 2004;27(9):2178-83. 
[136] Low PA, Nickander KK. Oxygen free-radical effects in sciatic-nerve in experimental diabetes. Diabetes. 1991;40(7):873-7.

[137] Stevens MJ, Lattimer SA, Kamijo M, Vanhuysen C, Sima AAF, Greene DA. Osmotically-induced nerve taurine depletion and the compatible osmolyte hypothesis in experimental diabetic neuropathy in the rat. Diabetologia. 1993;36(7):608-14.

[138] Hermenegildo C, Raya A, Roma J, Romero FJ. Decreased glutathione-peroxidase activity in sciatic-nerve of alloxan-induced diabetic mice and its correlation with bloodglucose levels. Neurochemical Research. 1993;18(8):893-6.

[139] Nickander KK, mcphee BR, Low PA, Tritschler H. Alpha-lipoic acid: Antioxidant potency against lipid peroxidation of neural tissues in vitro and implications for diabetic neuropathy. Free Radical Biology and Medicine. 1996;21(5):631-9.

[140] Low PA, Nickander KK, Tritschler HJ. The roles of oxidative stress and antioxidant treatment in experimental diabetic neuropathy. Diabetes. 1997;46:S38-S42.

[141] Ozkaya YG, Agar A, Hacioglu G, Yargicoglu P. Exercise improves visual deficits tested by visual evoked potentials in streptozotocin-induced diabetic rats. Tohoku Journal of Experimental Medicine. 2007;213(4):313-21.

[142] Ozkaya YG, Agar A, Hacioglu G, Yargicoglu P, Abidin I, Senturk UK. Training induced alterations of visual evoked potentials are not related to body temperature. International Journal of Sports Medicine. 2003;24(5):359-62.

[143] Kumar JSS, Menon VP. Effect of diabetes on levels of lipid peroxides and glycolipids in rat-brain. Metabolism-Clinical and Experimental. 1993;42(11):1435-9.

[144] Aguiar, A.S. \& Pinho, R.A. (2007). Effects of physical exercise over the redox brain state. The Revista Brasileira de Medicina do Esporte. 2007;13(5): 355-360.

[145] Floyd RA, Carney JM. Age influence on oxidative events during brain ischemia reperfusion. Archives of Gerontology and Geriatrics. 1991;12(2-3):155-77.

[146] Maiese K, Chong ZZ, Shang YC. Mechanistic insights into diabetes mellitus and oxidative stress. Current Medicinal Chemistry. 2007;14(16):1729-38.

[147] Alipour M, Salehi I \& Ghadiri Soufi F. (2012). Effect of Exercise on Diabetes-Induced Oxidative Stress in the Rat Hippocampus. Iran Red Crescent Medical Journal. 2012;14(4): 222-228.

[148] Kucukatay V, Hacioglu G, Ozkaya G, Agar A, Yargicoglu P. The effect of diabetes mellitus on active avoidance learning in rats: The role of nitric oxide. Medical Science Monitor. 2009;15(3):BR88-BR93.

[149] Tahirovic I, Sofic E, Sapcanin A, Gavrankapetanovic I, Bach-Rojecky L, SalkovicPetrisic $M$, et al. Brain antioxidant capacity in rat models of betacytotoxic-induced experimental sporadic Alzheimer's disease and diabetes mellitus. Journal of Neural Transmission-Supplement. 2007(72):235-40.

[150] Ozkaya GY, Aydin H, Toraman NF, Kizilay F, Ozdemir O, Cetinkaya V. Effect of strength and endurance training on cognition in older people. Journal of Sports Science and Medicine. 2005;4(3):300-13. 
[151] Cetin E, Top EC, Sahin G, Ozkaya YG, Aydin H, Toraman F. Effect of vitamin e supplementation with exercise on cognitive functions and total antioxidant capacity in older people. Journal of Nutrition Health \& Aging. 2010;14(9):763-9.

[152] Gomez-Pinilla F, Ying Z, Roy RR, Molteni R, Edgerton VR. Voluntary exercise induces a BDNF-mediated mechanism that promotes neuroplasticity. Journal of Neurophysiology. 2002;88(5):2187-95.

[153] Rosa EF, Takahashi S, Aboulafia J, Nouailhetas VLA, Oliveira MGM. Oxidative stress induced by intense and exhaustive exercise impairs murine cognitive function. Journal of Neurophysiology. 2007;98(3):1820-6. 